\title{
UM AMOR FICCIONAL FRAGMENTADO EM MEIO A CARTAS, BILHETES, POESIAS, CINEMA, MEMÓRIAS, LITERATURA, TEORIAS E EXPERIMENTAÇÕES
}

Julia Casotti é jornalista e mestranda em Literatura, Cultura e Contemporaneidade na PUC-Rio. Email: juliacnogueira@gmail.com

\section{O nosso "todo sentimento do mundo"}

Yuri, às vezes, muitas vezes (tenho que admitir), tenho vontade de te enviar uma carta. Hoje acordei e decidi escrever uma, para lacrar os velhos e bons tempos que passamos juntos. Lembrei hoje como você gosta de Carlos Drummond de Andrade, como nós dois líamos juntos as poesias daquela edição surrada de "Sentimento do mundo" que compramos no sebo da Barata Ribeiro, num sábado chuvoso. O nosso verso preferido era:

"Tenho apenas duas mãos

e o sentimento do mundo, mas estou cheio de escravos,

minhas lembranças escorrem

e o corpo transige

na confluência do amor".

Pela manhã, me pego lendo em voz em alta essa primeira estrofe da poesia de Drummond. Sorrio sozinha, e lembro também do seu sorriso de criança. E da nossa mania de decorar os trechos favoritos de nossos livros preferidos. Será que posso assumir e dizer em voz alta que sinto saudades?

\section{Hoje eu entendo melhor}

Ei, como você está? Por aqui, tudo uma correria. Antes de mais nada, queria te pedir um favor. Dessa vez, você poderia responder minha correspondência mais rápido? Tenho pouca paciência para esperar. Tenho ainda mais agonia quando se trata de esperar tantos dias para ler o que você achou das minhas últimas palavras. Queria te dizer que hoje eu entendo melhor. Sabe que, antes, tampouco eu conhecia a extensão do nosso sentimento.

Era como se o esticássemos a cada dia um pouco e, quando mais o esticávamos, mais entendíamos que ele iria até onde quiséssemos. Ele não tinha fronteiras, não tinha tamanho, era uma presença que se fazia mais forte do que a precariedade da carne. Também não tinha tempo, e foi só mais tarde, que compreendi o que na época estava misturado com dor. Hoje, sei exatamente o que significa esse sentimento entre nós. Hoje tudo faz mais sentido. Hoje, no presente. Porque no passado eu não conseguia enxergar bem, nem eu e nem você. Tudo era muito estranho e tinha um gosto salgado. Um gosto salgado de lágrimas. 


\section{Des-lo-ca-men-to}

Eu desloco, tu deslocas, ele desloca, nós deslocamos, vós deslocais, eles deslocam. Esse substantivo, no masculino singular, é a sua cara. Tenho estudado bastante o deslocamento. Não como no conceito da Física, em que a ação é uma grandeza vetorial definida como a variação de posição de um corpo em um dado intervalo de tempo. Mas pelas teorias do filósofo francês Jacques Rancière, ou por meio da forma de narrar de Machado de Assis.

Sim, Yuri, Rancière, nascido em 1940, e Machado, em 1839, podem dialogar. Quem disse que não? Aposto que agora você tá aí, rindo da minha cara. Eu sei bem que você adora rir das minhas comparações criativas ou malucas. Mas, vai, essa faz sentido. Vou te explicar como 2 e 2 podem sim ser 4 - diferente do que o Roberto Carlos costuma dizer desde 1971 (até coloquei na playlist a música cantada na voz divina maravilhosa de Gal).

Entre os regimes criados por Rancière para se pensar a arte, o estético seria o mais glorioso, momento quando a arte se transforma em autônoma e promove deslocamentos, mobilidades e reconfigura as relações. O regime estético é sinônimo da leitura dos detalhes da obra, de identificar os sinais que ampliam a visão do espectador e enxergam o que está por trás das aparências. Para o filósofo francês, a arte contemporânea deve ser democrática, sendo responsável por fazer as pessoas se deslocarem de suas próprias vidas ao observarem um quadro ou uma instalação artística, provocando identificação ou não com outros mundos, com outros personagens.

E nesse contexto é que a ficção seria o dispositivo ideal de compreensão do mundo, já que permitiria esse tipo de deslocamento e possibilidades de imaginação. Na visão do francês, essa revolução aconteceria primeiro na literatura realista, no momento em que a vida dos anônimos, os detalhes, o banal, os momentos corriqueiros ganhariam destaque nas histórias contadas por escritores, como Balzac, Flaubert e também Machado de Assis durante o século XIX.

Machado não está a serviço da criação de heróis. Ele utiliza estratégias modernas antes mesmo do modernismo, não é moralista e constrói com humor irônico o comum da vida dos homens, o banal, o corriqueiro - assim como valoriza Rancière. O escritor brasileiro está entre a tradição romântica e realista/naturalista, investe em uma leitura fragmentada, de forma livre, híbrida, feita de deslizamentos. Como diz meu professor, é um provocador de mal-estar.

Agora, por que mesmo estou falando tudo isso? Isso é a nossa cara, esses assuntos mutantes (estou rindo sozinha em voz alta na sala, olhando pra rede que você tanto gostava de se deitar). Começamos falando de signos e terminamos em uma

discussão sobre política russa. Consegui misturar filosofia, música, literatura e divagações nessa carta. Acho que são os deslocamentos e os deslizamentos a cara da nossa relação. 


\section{Anacronismo}

Nós somos anacrônicos? Às vezes me pergunto isso. Parece que não conseguimos nos adaptar a tantas coisas, como à exposição demasiada nas redes sociais, ou à intensidade das relações e, logo depois, ao término delas. Você bem sabe que eu vivo de remoer o passado. Eu sei que isso me corrói. Mas não consigo evitar. Pelo menos, não por esses últimos meses.

Parece que eu vivo meu passado todos os dias. Eu repito pra mim mesma tudo o que eu consegui falar e tudo o que ficou entalado das nossas discussões. Fico triste comigo, mas logo depois entendo que não preciso mais disso, que já passou, que consegui fazer o que foi possível naquele ano, que naquele ano eu estava muito frágil. Foram muitas mudanças de uma só vez. Tenho que parar de me cobrar tanto.

A questão é que sinto que estou dissociada do meu tempo todos os dias. Não vivo o presente. Vivo o passado, Yuri. Vivo os dias que vivi com você. Vivo aquela São Paulo fria, chuvosa, aquela Avenida Paulista terrível, daquele dia que caminhamos quilômetros em silêncio pra nada. Na verdade, pra ter uma despedida sem abraço, sem mal te olhar, muito menos te beijar. Eu vivo de relembrar todas as vezes que você me magoou. É difícil estar inteira aqui no Rio de Janeiro ainda vivendo de lembrar-me de São Paulo.

\section{Agamben}

Hoje estou com pressa, por isso o tempo é só para te enviar um bilhete. Peço desculpas adiantadas, essa semana o trabalho me tomou todas as horas criativas. Mas é que li um livro do Giorgio Agamben, o filósofo italiano, e lembrei-me de você - pra variar. Ele diz em "O que é o contemporâneo e outros ensaios" que contemporâneo é aquele que recebe em pleno rosto o facho de trevas que provém do seu tempo. E que ser contemporâneo é, antes de tudo, uma questão de coragem: porque significa ser capaz não apenas de manter fixo o olhar no escuro da época, mas também de perceber nesse escuro uma luz que, dirigida para nós, distancia-se infinitamente de nós. Ou ainda: ser pontual num compromisso ao qual se pode apenas faltar. Fiquei me perguntando se poderia ser considerada uma "contemporânea" a partir dessa definição de Agamben. Coragem, pelo menos, eu tenho.

\section{Corpo}

Você ignorou minha pergunta na última carta. Bem seu jeitinho fugir de conflitos, dos meus questionamentos, das minhas indagações. Você nunca vai mudar? Ainda espero o dia que você vai encarar com o seu corpo o nosso relacionamento.

\section{Cinema de domingo}

Tem dois filmes brasileiros em cartaz aqui no Rio que valem o ingresso e o deslo-ca-men-to. "Avanti popolo", de Michael Wahrmann, e "Os dias com ele”, de Maria Clara Escobar. Os dois longas-metragens são produções brasileiras e têm como pano de fundo as memórias em torno da ditadura militar. Ouviu falar por São Paulo também? 
O filme de Wahrmann conta a história de André, personagem que encontra várias películas filmadas por seu irmão durante a ditadura e relembra as histórias vividas por seu pai, que ainda busca o filho desaparecido há mais de trinta anos. E no filme de Maria Clara, a diretora investiga o passado de seu pai, Carlos Henrique Escobar, um intelectual que foi preso e torturado durante a ditadura no Brasil. O interessante é que Carlos não fala sobre o assunto desde aquele tempo.

A impressão é do resgate de uma memória nostálgica, de certa forma, sofrida, melancólica. Falar da ditadura militar no país não é fácil, é assunto doloroso, mas acredito ser pauta importante para lembrar sobre as reconfiguradas "ditaduras" que ainda existem no país. O que é essa violência policial nas manifestações, por exemplo? E essa briga que envolve a publicação de biografias no país? Enfim, esses assuntos rendem cartas infinitas, eu sei. Mas andei me questionando sobre isso esses dias.

\section{Feriado do adeus}

Sabe do que eu lembrei? Daquele feriado que passei em São Paulo. Nós almoçávamos em casa, você gostava de cozinhar, e o meu voo era quase sempre no fim da tarde, o horário possível porque na manhã seguinte eu precisava estar no trabalho, e por volta das cinco horas você me levava até o aeroporto e eu sempre imaginava como seria a última vez, se você me daria essa carona, se haveria um abraço ou beijo de despedida, no saguão ou em frente à placa do embarque doméstico, ou se eu sairia sem olhar para trás e desceria de escada para chegar mais rápido à rua e dali arrumar um táxi enquanto você olhava para a porta fechada e o apartamento vazio e a cama desfeita e então podia sentar e se encolher e respirar fundo e fechar os olhos e então como que desabar numa agonia que derrota todas as partes do corpo.

Naquele dia, eu dei a notícia da forma mais objetiva que consegui, e embora pudesse falar sobre tristeza e pena e culpa a lembrança mais nítida que tenho da época é de uma sensação envergonhada de alívio, e de tudo o que aprendi nos anos que passei com o meu primeiro namorado, quer dizer, as lições que um primeiro relacionamento traz, a primeira vez que alguém diz que gosta de você, a primeira vez que você aceita isso, e como você lida com isso, e como se comporta diante da infinidade de problemas que isso traz, o jeito como você fala, a maneira como você se veste, o quanto você é egoísta, o quanto é descuidado e mentiroso e manipulador, o quanto é inconstante e imaturo e inconfiável em aspectos tanto afetivos quanto comezinhos do dia a dia em que só reforça a carga de opressão sobre a outra pessoa, enfim, de tudo o que aprendi nos anos em que não parei de ser acusada e julgada e condenada pelo meu primeiro namorado, pelo que era e nunca deixaria de ser por falta de esforço e comprometimento em relação a ele, nada é mais importante que a certeza de que fiz a coisa certa naquele feriado, Yuri.

\section{“Napoleão", o filme}

Você pediu, quase implorou, que eu visse o filme "Napoleão", de 1927, do diretor francês Abel Gance. Caramba, 222 minutos de um filme mudo, Yuri? Não sei se vou ter paciência, já quero ser logo sincera com você. Detesto criar falsas expectativas 
nos outros, principalmente em você. É uma drama épico de guerra, né? Vi que tem produção francesa, sueca e italiana. Também tem uma sinopse que elogia o longametragem.

"Considerado por muitos um filme muito à frente de seu tempo, esta é uma cinebiografia de Napoleão Bonaparte, mostrando sua vida desde a escola, passando pela Revolução Francesa e pela invasão da Itália em 1797, onde o filme para. Na realidade, esta é a primeira parte de uma série de filmes, porém o diretor apenas conseguiu dinheiro para a primeira parte".

Em outra sinopse, diz: "obra indispensável aos amantes da $7^{a}$ arte. Napoleão, de Abel Gance, é uma obra-prima absoluta, desde os primeiros anos de vida, do mais controvertido e importante personagem da História da França. Após infindáveis remontagens, o clássico estreou em Paris, com grande sucesso, em abril de 1927. O filme mostra a infância de Napoleão, seus dias de escola, até chegar à fase adulta. Nessa época o jovem Bonaparte vai para a Córsega passando a fazer parte da Revolução Francesa. Logo, se transforma num grande estrategista, somando ao currículo incrível e vitoriosas batalhas. Além das técnicas de filmagem e da forma de contar a história, o filme ganhou reputação por causa dos últimos 20 minutos, nos quais o diretor alternou sequências panorâmicas em widescreen com complexas imagens múltiplas, que eram projetadas simultaneamente em três telas. Maravilhoso e perfeito".

Está bem. Acho que me rendi à "obra indispensável aos amantes da $7^{\mathrm{a}}$ arte". Vou ver na semana que vem e compartilho minhas impressões.

\section{A uma passante, Charles Baudelaire}

A rua em derredor era um ruído incomum, longa, magra, de luto e na dor majestosa, Uma mulher passou e com a mão faustosa Erguendo, balançando o festão e o debrum; Nobre e ágil, tendo a perna assim de estátua exata.

Eu bebia perdido em minha crispação

No seu olhar, céu que germina o furacão,

A doçura que embala o frenesi que mata.

Um relâmpago e após a noite! - Aérea beldade,

E cujo olhar me fez renascer de repente,

Só te verei um dia e já na eternidade?

Bem longe, tarde, além, jamais provavelmente!

Não sabes aonde vou, eu não sei aonde vais,

Tu que eu teria amado - e o sabias demais!

Vamos (re) viver nosso (ex) amor fugaz? 


\section{Que tal criarmos a nossa própria narrativa etnográfica?}

Nosso relacionamento conturbado daria uma bela narrativa etnográfica, daquelas pra entender a etnografia da cultura de um amor. No fazer etnográfico, a teoria e a prática são inseparáveis, uma perpassando pela outra o tempo todo. E, como diz a antropóloga Mariza Peirano, é preciso permitir-se ser surpreendido pelo campo de pesquisa, pelo campo de ação, deixando, muitas vezes, as teorias somente para as páginas empoeiradas de alguns livros. Em minha opinião, a nossa narrativa etnográfica seria completamente curiosa e surpreendente. Nenhuma teoria comportaria nossa prática. Na nossa história poderíamos até abusar da invenção e ficcionalidade, só pra tudo ficar mais dúbio, repleto de metáforas, do jeito que a gente costuma inventar todos os dias o nosso amor. Daí, podíamos brincar daquele recurso que eu adoro - muito utilizado nos livros e no cinema -, que é quando o autor/diretor/ator desmonta o exercício ficcional na frente do público. De forma espontânea, participamos ativamente da história, com o aparente poder de opinar, desvendar mistérios, de acompanhar de perto os personagens. A constante presença do leitor/espectador, entrando no universo do estatuto de ficcionalidade, me encanta.

\section{Quanta asneira!}

Sabe que me recordei de um amigo nosso, companheiro de mesa e cerveja no Bar Central, rapaz cheio de vida, alegre, satisfeito, corado, atlético. Dedicava-se também aos esportes. Seu único desespero: não conseguir escrever algo de valor, ou mesmo que despertasse o nosso elogio. Eram uns continhos chinfrins e sem enredo, sem personagens caracterizados, escritos numa língua cheia de solecismos. Realmente não havia lugar para ele na literatura. Devia esquecê-la o quanto antes. Um dia, confidenciou-me que ficava feliz quando o seu corpo adoecia. Sentia-se preso à casa, à escrivaninha, às leituras. Nunca mais soube dele. Tenho certeza, no entanto, que se encaminhava para ser o primeiro mártir da literatura. Confinava seu corpo sadio à doença para que a mente se desenvolvesse. Quanta asneira!

\section{Do avesso}

Doze meses sem te ver. Depois de doze meses sem te ver, nos encontramos no calçadão da praia de Copacabana e você disse a primeira coisa que pensou: você está igual. Está igual, continua sendo assim, exatamente do jeito que você é. E eu continuo sendo do avesso, sempre fui do avesso, e agora quem sabe eu lhe conte que no Rio de Janeiro fiquei ainda mais do avesso, completamente do avesso. Depois do nosso encontro, em vez de ir para o meu apartamento, fiz sinal para um táxi e pedi ao motorista que apenas dirigisse. Repeti, expliquei e até dei o dinheiro adiantado para o taxista: siga em qualquer direção, rode em círculos, em diagonais, tanto faz, eu desço do seu táxi quando eu sentir vontade. Foi uma longa viagem, sem música, de Copacabana até Madureira. Durante o trajeto, eu não consegui responder a nenhuma das perguntas que o motorista de táxi me fez. Não o escutei. 


\section{Performance}

Esqueci de te contar, mas antes de ontem fiz uma performance de mim mesma lendo um texto autobiográfico. Na universidade, pediram esse trabalho final de uma das disciplinas. Tentei criar uma tensão do texto com a fala e a escrita. Meu texto foi tudo menos ingênuo, quis trair o texto autobiográfico careta convencional.

Criei um jogo entre a primeira e a terceira pessoa, brinquei com as linguagens cotidiana e a extremamente sofisticada. Minhas palavras não tiveram profundidade alguma. Na verdade, a performance desviou do relato autobiográfico. Você deve estar se perguntando de onde eu tirei a ideia. Aposto que sim. Tudo bem, eu conto. Conhece o crítico literário Silviano Santiago? Aproveita que tem novo livro dele lançado. O nome é "Mil Rosas Roubadas", e é baseado na amizade entre o autor e o produtor cultural Ezequiel Neves. É o próximo livro da minha lista de férias.

\section{Sem rótulos, por favor!}

Sabe de que tipo de livro eu gosto? Daqueles que nenhum rótulo dá conta. É romance, é autobiografia, ao mesmo tempo em que o texto é cercado de desconstrução da narrativa intimista e da ideia confessional. Um texto que é produzido sem a construção da dúvida, mas pela tentativa de respostas. Pode ser uma literatura de experiência urbana que, na verdade, a cidade não é cenário e sim personagem. Ou algum livro que recusa idealizar o romantismo e o realismo, mas também é um romance realista. Adoro aqueles que optam pelo humor, ironia, sátira e descartam a poética da emoção, do sentimentalismo exagerado. Detesto sentimentalismo exagerado, mesmo que tantas vezes já tenha me questionado: pra quê tanta emoção de mulherzinha nessas cartas, mulher?

\section{Trauma tem nome e sobrenome}

Você adora se fazer de vítima. Lá vem você me escrevendo aquele e-mail como um testemunho. Um testemunho recheado de traumas. Eu não tenho pena de você, Yuri. Não adianta você vir com esses "coitadismos" pra me dobrar. Hoje, não. Não vou cair na sua lábia, nas suas poesias, nas suas declarações tão banais de amor imensurável. Você que me deixou um trauma. Passei 365 dias remoendo nossa história, aturando suas instabilidades, seu egoísmo. Não há nada tão catastrófico assim para os seus dramas, e nosso relacionamento tampouco é um acontecimento histórico. Para de querer ser o dono da verdade, testemunhando numa função de certificar os acontecimentos e comprovar a "sua verdade". No seu caso, essa necessidade de testemunhar, além de demandar uma irreal justiça, reforça a sua heroicização nesse relato mal contado. Para de escrever de um jeito que se aproxima de uma verossimilhança inventada, querendo que eu acredite nas suas palavras escorregadias. Me deixa em paz.

\section{Pensamento fugaz}

Ler é cobrir a cara, pensei esses dias. Ler também é abrir uma porta que nunca se fecha. Ler é cobrir a cara, é abrir uma porta. E escrever é mostrá-la, é entrar nessa porta aberta. 


\section{Amor cubista}

Nosso amor foi (ainda é) cubista? Recortado, fragmentado, repleto de formas nunca completamente entendidas, em uma total renúncia de perspectiva? Somos uma obra de Pablo Picasso ou de Juan Gris? Sei que Picasso leva a fama Brasil afora, mas Gris é meu predileto. Gosto dos quadros coloridos, com desenhos de barco, violão ou daquelas mulheres geométricas incríveis. Podemos ser também uma obra do pintor Mondrian. Obras que passam por relações entre arte, design, arquitetura, urbanismo e apontam para uma disseminação da forma que ultrapassa o limite restrito de um plano pictórico. Nossa narrativa é feita de flashes. Nosso romance é uma bricolagem.

\section{Hoje a memória é pra ser esquecida}

Não quero entender nossa memória como lugar de preservação, do ressentimento, de reificação, manutenção, muito menos da monumentalização. Porque o monumento não comemora, não celebra algo que se passou, mas transmite para o futuro as sensações persistentes que encarnam o acontecimento: o sofrimento sempre renovado dos homens, seu protesto recriado, sua luta sempre retomada. Tampouco gosto da ideia de memória melancólica, nostálgica, que me entristece. Agora, sei muito bem que às vezes é importante prevalecer a memória como lugar do apagamento, esquecimento, da amnésia. Seguir em frente é deixar o passado pra trás, é não ousar lembrar de como fui feliz ao seu lado.

Às vezes acordo e me esforço para não lembrar da viagem a Rio das Ostras, do festival de jazz e blues frio da cidade de praia. De não lembrar dos nossos jantares permeados por trilhas sonoras e, lá pelas tantas, você bêbado, me contando os segredos de infância. De você, ao tocar violão para impressionar se achando um galã de cinema, vaidoso que só, leonino que só. Sei que você vive me dizendo que memória é pra ser ativada, que é lugar de (re) invenção. Mas hoje acordei com o pé esquerdo. Quero mais a memória do apagamento, do esquecimento. Eu quero é te esquecer, te deixar dentro da gaveta do armário que nunca abri desde que cheguei ao Rio de Janeiro.

\section{Formas de tentar me perder}

Sabe que caminhei ontem à noite durante horas. Era como se quisesse me perder por alguma rua nova. Me perder absoluta e alegremente. Mas há momentos em que não podemos, não sabemos nos perder. Ainda que tomemos sempre as direções erradas. Ainda que percamos todos os pontos de referência. Ainda que se faça tarde e sintamos o peso do amanhecer enquanto avançamos. Há temporadas em que, por mais que tentemos, descobrimos que não sabemos, que não podemos nos perder. $\mathrm{E}$ talvez tenhamos saudade do tempo em que podíamos nos perder. O tempo em que todas as ruas eram novas.

\section{$O$ cinema da fome}

Entre os filmes do Glauber Rocha "Deus e o diabo na terra do sol" (1964) e 'Terra em Transe" (1967), qual você gosta mais? Queria escolher um dos dois para começar a entender a importância desse homem de Vitória da Conquista (BA) para o cinema brasileiro, para o Cinema Novo que, como lema, carregava "uma câmera na mão 
e uma ideia na cabeça". Quero ver mais dessa estética do cinema da fome, fome de Brasil, fome de mudança, essa estética precária tão presente nos filmes de Glauber. Há ali uma poética do deslocamento, em que não importa a qualidade de quem faz esse cinema, mas sim onde ele está e por quem ele é feito. Glauber tinha desejo, vontade de transformação. Enfim, qual você indica?

\section{A vida sem você}

Eu acordava e antes de preparar o café ligava o computador e o celular. Checava os e-mails e a caixa postal para ver se havia algum sinal seu. Meus pensamentos tinham um único objetivo: você. Vinte e quatro horas por dia, quando comia, quando trabalhava, quando tomava banho, quando dormia, só pensava em você. Checava novamente os e-mails: propagandas, amigos convidando para sair ou pedindo favores, informações de palestras ou cursos. De você, nada, nem uma palavra, nenhum sinal. Ia para o quarto e deitava na cama ainda desfeita. As cortinas fechadas como se fosse noite. Debaixo da coberta, olhava o teto e me perguntava se um dia isso passaria, se um dia eu deixaria de pensar em você. Já hoje, tudo mudou. Como o mundo dá voltas, mesmo que essa frase pareça ser um grande (verdadeiro) clichê das comédias românticas norte-americanas. Como é cruel (e bonito) que a vida continue depois de você.

\section{Notas de até breve}

Os escritos experimentais acima fizeram parte do trabalho final da disciplina "Literatura Contemporânea I" (2014.1), do mestrado em Literatura, Cultura e Contemporaneidade da PUC-RJ. É a vontade (e tentativa) de inventar, de samplear textos da literatura contemporânea, misturando minha própria escrita com a de outros autores, de fugir do óbvio, das teorias pesadas e citações teóricas que marcam as monografias dos programas de pós-graduação. Porque se em alguma disciplina ficou claro que é possível e preciso imaginar/construir outras histórias, foi a ministrada por Júlio Diniz. A princípio, a intenção era fazer algo totalmente teórico. Mas, inspirada na última aula da disciplina e na extensa lista de livros lidos para o curso ao longo do primeiro semestre de 2014, decidi fazer diferente. A ideia foi misturar um pouco do que foi discutido, desde impressões dos alunos, questionamentos suscitados após as discussões em sala de aula, até ponderações e exposições de Júlio. Teorias, teóricos, escritores, poetas, cinema, música, memória, testemunho e muita literatura estão fragmentados nos escritos de um amor ficcional criados nessas páginas brancas de Word. 


\section{REFERÊNCIAS}

AGAMBEN, Giorgio. O que é o contemporâneo? E outros ensaios. Chapecó, SC: Argos, 2009.

ALMEIDA, Manuel Antônio de. Memórias de um sargento de milícias. São Paulo: Martin Claret, 2012.

ALMEIDA, Maria Izabel Mendes de. Por que não? Rupturas e continuidades da contracultura. Rio de Janeiro: 7 Letras, 2007.

ANDRADE, Oswald de. Memórias Sentimentais de João Miramar. Rio de Janeiro: José Olympio, Civilização Brasileira, Editora Três, 1973.

ASSIS, Machado de. Memórias Póstumas de Brás Cubas. São Paulo: Martin Claret, 2012.

DANTO, Arthur C. A transfiguração do lugar-comum: uma filosofia da arte. São Paulo: Cosac Naify, 2010.

GUTFREIND. Cristiane Freitas. O realismo e a catástrofe histórica nos filmestestemunho. São Paulo: Revista de Cultura Audiovisual da Universidade de São Paulo (USP), 2011.

LAUB, Michel. Diário da Queda. São Paulo: Companhia das Letras, 2011.

LEVY, Tatiana Salem. A Chave de casa. Rio de Janeiro: Bestbolso, 2013.

PEIRANO, Mariza. A favor da etnografia. Rio de Janeiro: Relume-Duamará, 1995.

RANCIÈRE, Jacques. A partilha do sensível. São Paulo: EXO experimental org.; Editora 34, 2009.

O destino das imagens. Rio de Janeiro: Contraponto, 2012.

SANTIAGO, Silviano. Em Liberdade. Rio de Janeiro: Rocco, 2013.

. Eu e as galinhas d'angola. In: OLINTO, Heidrun e

SCHOLLHAMMER, Karl Erik. (org.). Literatura e Memória. Rio de Janeiro: Edições Galo Branco, 2006, p.21-32.

ZAMBRA, Alejandro. Formas de Volta para Casa. São Paulo: Cosac Naify, 2014.

Bonsai. São Paulo: Cosa Naify, 2012. 


\section{SITES PESQUISADOS}

Site Ilustríssima. Disponível em

<http://www1.folha.uol.com.br/ilustrissima/2014/06/1466194-silviano-santiagoprocessa-verdade-e-invencao-em-novo-livro.shtml> Acesso em 15 de junho, 2014.

Site E-biografias. Disponível em: http://www.e-biografias.net/glauber_rocha/pegar Acesso em 12 de junho, 2014.

Site Revista Cinética. Disponível em:

<http://www.revistacinetica.com.br/osdiascomele.htm> Acesso em 12 de junho, 2014.

Site Zero Hora. Disponível em:

$<$ http://zh.clicrbs.com.br/rs/entretenimento/noticia/2014/06/avanti-popolo-mostra-paiamarrado-a-eterna-espera-pelo-filho-desaparecido-na-ditadura-4523949.html > Acesso em 15 de junho, 2014.

Site Cine Player. Disponível em:

<http://www.cineplayers.com/filme/napoleao/1043 > Acesso em 18 de junho, 2014.

Site Adoro Pipoca. Disponível em: 〈http://www.adorocinema.com/filmes/filme-645/> Acesso em 18 de junho, 2014. 